\title{
Enthusiasm and the College Compact
}

\author{
L. V. Morris
}

Published online: 15 September 2013

C Springer Science+Business Media New York 2013

It is almost fall in Athens, Georgia, and a new academic year is now underway. Excitement fills the air as the undergraduate students locate their residence halls or apartments, unload boxes from cars, greet old friends and roommates, and in general exhibit high hopes and expectations for the year ahead. Celebrations abound. We are one week into the term, and I have already attended a dozen or more welcome back receptions and convocations, with another one scheduled for this Sunday evening to celebrate the newly occupied Rutherford Hall. The original 1939 Rutherford Hall was razed in 2012, surrounded by a fair amount of local and statewide controversy stemming from historic preservationists and alumni who hold dear memories of living in the old dormitory. However, that story will hold for another day. The new and improved Rutherford Hall is busy sheltering new students and becoming part of future memories.

Students are barely unpacked when they head for Sanford Stadium, where they participate in a recently established, but highly popular, new tradition at the University of Georgia (UGA). On the Sunday evening before the start of classes, a small number of administrators and faculty join the first-year students in Sanford Stadium, the 80,000+-seat venue for the University of Georgia football games, to watch the first-year students form a big $\mathrm{G}$ on the playing field. Thankfully, the redcoat marching band marks the "G" with tiny flags and then leads the first-year students to fill in the outline. A group photo then captures the class, in this case, of 2017, and marks the beginning of the college experience. This is a powerful bonding experience, and unless students are football recruits they will not step on the grass of Sanford Stadium again until graduation.

As I watched the students on the field, I could see the hope written across the faces. I know they are a talented group, in fact the most academically qualified freshman class in the University's history: approximately 5,150 students with an average of 3.86 GPA and an SAT average of 1280. The 500+ honors students posted GPAs of over 4.0 and an SAT average of 1462. This group has what it takes to succeed. I wondered though what the future would hold for each of them as individuals; and I could feel the heavy responsibility faculty members across the disciplines have to impart knowledge, develop skills, shape attitudes, and nurture creativity.

Somehow we need to bottle the enthusiasm of new beginnings. On average, $84 \%$ of those entering UGA will step back onto the Sanford Stadium grass and graduate over the next 6 years, the standard timeline for calculating completions. The road will not be smooth for all,

L. V. Morris $(\bowtie)$

Institute of Higher Education, University of Georgia, 102 Meigs Hall, Athens, GA 30602-6772, USA

e-mail: lvmorris@uga.edu 
however, even for those who graduate. Many of these students enter while still in their teens, and they are faced with complex challenges and responsibilities in courses and beyond. Wisely, the Student Government Association has recognized the challenges for students, and through multiple collaborations with students and faculty developed "The University of Georgia Compact for Responsible Scholarship: A Joint Resolution for Academic Excellence" (https://www.capa.uga.edu/Capa/UGACompact3.pdf). This 2009 compact was endorsed by the UGA Student Government Association and the UGA Teaching Academy. The one-page document outlines the set of values and expectations that each holds for the other in the areas of communication, respect, and engagement. Each category lists one or more guidelines for behavior, for example under faculty guidelines, "clearly communicate expectations of students." For students, the compact states "attend every class and be on time" and "be honest with professors and other students." An aspirational statement, listed for both faculty and students, says "promote an academic atmosphere on campus." As you can tell, the Compact does not articulate general education learning outcomes; rather it provides guidelines for respectful and collegial behavior. Most of the statements, to a long-time educator, are common sense.

As I watched the first-year students forming the "G", I wondered how many came to college with common sense guidelines for success and thought about how their enthusiasm would be dampened following a bad decision. I wondered if we discussed the Compact on the first day of classes, across all of our courses, if it could make a difference for those students who might otherwise make bad choices. I believe students come to college with high hopes and a desire to accomplish great things. Practicing responsible scholarship is a pathway to achievement and an aid to enthusiasm. The Compact provides a guide to responsible behavior, and that may be as important for a successful college career as high GPAs and test scores. Here's hoping that the enthusiasm continues and that the accomplishments are many for the class of 2017! I look forward to your ideas on innovative practices in higher education. 